Voces

\section{INC, trasfondos y conductas de una arquitectura utilizada}

\author{
Pablo Rabasco Pozuelo \\ Universidad de Córdoba
}

Un hecho cierto es que en el Instituto Nacional de Colonización (INC) creó una serie de nuevas poblaciones en función de unos intereses de tipo económico-industrial determinados; esto fue asi y en buena parte de esta problemática se nos muestra representada una imagen apropiada para entender las bases del ideario social y económico de al menos los primeros diez años del franquismo. Pero aparte de la obvia presencia y determinación explícita que presenta esta intervención, estas poblaciones tuvieron una forma urbana determinada que escapa necesariamente de cuestiones únicamente productivas, reflejando una trama que nos puede conducir a entender algunas de las tendencias que en ellas se ven reflejadas.

Entre estas tendencias destacan dos de una forma explicita: el Tradicionalismo y el Paternalismo. Destramar los puntos de incidencia entre estas conductas es necesario para una visión correcta de las intenciones que cubren la apariencia y la certeza de la intervención urbana y su reflejo en la arquitectura que se propone.

Cierto es que el tradicionalismo se muestra como una idea mutable y diversa, pero es igualmente en ese punto donde su significado se hace perdurable en distintos ambientes políticos, sociales y religiosos. El tradicionalismo que se desarrolla en estos primeros años del franquismo parte del cambio político radical y actúa en negativo, desde un sistema democrático como el republicano más ligado a tendencias europeas hacia unos conceptos que se arrastraban desde el Antiguo Régimen, en un claro intento de anclarse en el propio territorio y de trabar el aperturismo que ya se había propuesto. No se trata sin embargo de enfrentarse a la imagen antitradicionalista mostrada por la ciudad en contraposición al mundo rural, sino de enaltecer a éste último para conseguir una mutación que se haga presente y ejemplo en todo el territorio nacional.

Pero al llevar esta idea a las nuevas poblaciones llevadas a cabo por el INC observamos cómo igualmente se potencia una desmesurada visión negativa de la situación social y moral del mundo rural heredado, produciéndose una fuerte contradicción en el proceso. Se apoya y sublima el mundo rural y a la vez se potencia una visión decadente en cuanto a su situación moral, espiritual y cultural. Queda claro que se tenía que partir de una feroz crítica diferenciadora con la situación anterior para comenzar a trabajar desde unos presupuestos mínimos. Se llegará a plantear la existencia en el mundo rural de un daño difícilmente recuperable para lo cual se necesita una amplia y esforzada labor en la que los poblados del INC han de ser un ejemplo intachable.

Al considerarse en este sentido que esta población rural se encontraba fuera de la moralidad, la religión e incluso la higiene, se pierde ese baluarte que sustenta de alguna manera el espíritu tradicionalista, hay que reinventarlo. Aquí, en este momento, es cuando surge la figura paternalista que no ha olvidado lo que en el pasado significó el mundo rural y los valores que en él estaban depositados.

Pero la actuación del INC fue más allá cuando se instauró una política selectiva de los colonos basada en tres pilares fundamentales; aspectos técnicos, económicos y sociales que se presentaban con un carácter indivisible, trinitario.

En cuanto al proceso de elección técnica de los colonos habria que aclarar que, en general, sufrió numerosas críticas. En la elección se valoró las cargas familiares de cada colono, potenciándose el acceso a los nuevos pueblos a aquellas familias con mayor número de hijos y con rentas más bajas. Las críticas fueron orientadas a las dificultades que se pudieron plantear, de potenciar estos valores de indole social ante los de carácter técnico, además la baja capacidad económica de las familias pudo dificultar el crecimiento económico del pueblo a través de la inversión. En todo caso, la crítica hubiera sido posible igualmente si se hubiera producido una situación inversa a la que se dio en la mayoría de los casos. De lo que se trata es de hacer una operación no sólo rentable en el terreno económico y social, sino igualmente en el terreno de las ideas. Crear una serie de nuevas poblaciones con unos hombres elegidos por sus condiciones propicias en torno a los tres ejes básicos, de entre los cuales las determinaciones sociales serán las que verdaderamente tengan un impacto decisivo en la conformación urbanistica de las nuevas poblaciones y en las determinaciones ideológicas del régimen politico.

La tendencia tradicionalista y paternalista que el I.N.C. muestra en su política colonizadora habrá pues que delimitarla cuidadosamente. Son diferentes los campos de aplicación y diferentes son las instituciones y estructuras político-sociales que entran en esta dinámica. No creo equivocarme al afirmar que, si bien podemos hablar de tres ejes diferenciados en el campo social como son catolicismo, educación y moral, todos giran de una u otra forma alrededor del primero pues estamos hablando de una educación católica y de una moral o conducta también católica.

Por otro lado, las vías de control aplicadas a los arquitectos son conocidas, pero éstas no se vieron como tales en su momento sino como indispensables, aceptándose con normalidad. La determinación de crear un espacio religioso como eje fundamental dentro de los poblados no se hizo despreciando o relegando el entramado administrativo sino fusionándolos, creando una interesante confusión entre religión y ente público. Cierto es que en un primer momento se observa una clara intención por parte de la iglesia católica de establecer un control en los proyectos arquitectónicos, como en el caso del poblado del Cortijo de San Isidro en Aranjuez, donde se observa una tendencia a apartarse de una arquitectura rural para acercarse a propuestas historicistas, en la línea que igualmente seguía la política cultural franquista. Pero este control tan determinado se aleja de la idea de crear ese nuevo mundo rural, sencillo y humilde que se perseguía, girándose desde estas posturas historicistas hacia un nuevo regionalismo que realmente tampoco fue efectivo en muchos de los proyectos aunque se mantuvo ese ideal estilístico. 